\title{
Out of our skull, in our skin: the Microbiota-Gut-Brain axis and the Extended Cognition Thesis
}

\author{
Federico Boem $^{1}$ (D) $\cdot$ Gabriele Ferretti $^{2,3} \cdot$ Silvano Zipoli Caiani ${ }^{1}$
}

Received: 17 March 2020 / Accepted: 15 February 2021 / Published online: 1 March 2021

(C) The Author(s) 2021

\begin{abstract}
According to a shared functionalist view in philosophy of mind, a cognitive system, and cognitive function thereof, is based on the components of the organism it is realized by which, indeed, play a causal role in regulating our cognitive processes. This led philosophers to suggest also that, thus, cognition could be seen as an extended process, whose vehicle can extend not only outside the brain but also beyond bodily boundaries, on different kinds of devices. This is what we call the 'Externally Extended Cognition Thesis.' This notion has generated a lively debate. Here, we offer a novel notion of extended cognition, according to which cognition can be seen as being realized (and expanded) outside the brain, but still inside the body. This is what we call the 'Internally Extended Cognition Thesis'. Not only our thesis but also our approach while defending it is innovative. The argument we offer is supported by recent empirical findings in the life sciences and biomedicine, which suggest that the gut microbiota's activity has a functional role in regulating our cognitive processes and behaviors. In doing so, we embrace the holobiont-perspective, according to which it is possible to claim that what we call biological individuals are not autonomous entities with clear boundaries, but should rather be seen as networks of multiple interactions among species. Thus, by analyzing different sets of evidence in light of the holobiont-perspective, we argue that the gut microbiota could be seen as a component of our organism. On the basis of the philosophical interpretation of this evidence, however, we also suggest that there are no impediments standing the way of considering the gut microbiota also as a functional extension of our cognitive system. If so, this amounts to extending cognition out of 'our skull', though still confining it within 'our body': to 'our gut'. This is an instance of the 'Internally Extended Cognition Thesis,' whose benefits for an original (biologically informed) theory of extended cognition are discussed.
\end{abstract}

Keywords Microbiota $\cdot$ Extended cognition $\cdot$ Holobiont $\cdot$ Symbiosis $\cdot$ Functionalism $\cdot$ Biological individuality

Federico Boem

federico.boem@gmail.com

Extended author information available on the last page of the article 


\section{Introduction}

Are our cognitive processes entirely realized by the activity of our brain, or do they also extend beyond the 'boundaries of our skull'? Over the last decades, following the seminal paper by Andy Clark and David Chalmers (1998), the idea that cognition is not always and necessarily confined to individual brains has gained an increasing consensus, triggering a heated debate about the very individuation and location of cognitive processing (Adams and Aizawa 2007; Carter et al. 2018; Clark 2010b; Menary 2010; Rupert 2004; Wilson 2014; Gallagher 2018). According to this view, also known as the 'Extended Cognition Thesis' (ECT), the physical states subserving human cognitive processing can extend beyond the boundaries of the individual brain, as to include, as proper parts, different aspects of the individual's body, along with the environment. The ECT mainly relies on what Clark and Chalmers named the 'parity principle' argument, according to which:

“(...) if, as we confront some task, a part of the world functions as a process which, were it to go on in the head, we would have no hesitation in accepting as part of the cognitive process, then that part of the world is (for that time) part of the cognitive process."

(Clark and Chalmers 1998, 8).

On the basis of this assumption, proponents of the ECT hold that the physical vehicles ${ }^{1}$ of the human cognitive function can coincide, at least in part, with structures and processes located outside the human nervous system.

The rationale of the ECT is a particular variety of the functionalist conception of the mind, also known as 'machine state functionalism' (Putnam 1960; Piccinini 2004). According to this view, what makes something a cognitive state does not depend on its internal constitution, but rather on the causal role it plays within the physical system of which it is a part. This view led scholars to maintain that the same cognitive state may be realized across a variety of different physical structures (Putnam 1967) — this serving as a premise for any argument concerning the possibility of Artificial Intelligence. Interestingly, this thesis is equally important as a ground for the 'parity principle' argument, which is at the basis of ECT. Such an argument states, following Clark and Chalmers, that:

All the components in the system play an active causal role, and they jointly govern behavior in the same sort of way that cognition usually does. [...] The external features here are just as causally relevant as typical internal features of the brain.

(Clark and Chalmers 1998, 8)

This paper starts from this idea but proposes an original claim, regarding extended cognition, which is innovative in the literature. We argue that it is possible

\footnotetext{
1 Just a clarificatory remark on terminology. When talking about cognition, one can distinguish between cognitive functions, e.g. reasoning, perceiving, remembering, and the vehicles subserving these functions - most of the time conceived as specific 'brain realizers' of such functions.
} 
to distinguish between two different versions of ECT, depending on how much we are willing to extend the vehicles of our cognitive function outside of 'our heads', but, still, within 'our bodies'. Let us explain more carefully.

On the one hand, cognitive processes can be conceived as extending outside 'our heads' and bodies, involving objects and events in the physical environment. Let us call this notion the 'external extension' of cognition (EEC). On the other hand, we can consider the possibility for the vehicles of our cognitive functions to extend out of 'our heads', while, however, not exceeding the boundaries of 'our body'. Let us call this notion the 'internal extension' of cognition (IEC). Despite their differences, both EEC and IEC share the assumption that human cognitive processes are not realized by structures of the (central) brain-nervous system exclusively, but also by physical states that can reside outside 'our skulls', but, still, inside 'our body'. In this respect, as the reader can realize, both EEC and IEC are instances of ECT.

Now, EEC has attracted the attention of prominent scholars in the fields of epistemology, philosophy of mind, and cognitive sciences (e.g., Carter et al. 2018; Marsh 2010; Menary 2010). However, it has also been the target of several strong critical arguments (e.g., Frederick Adams and Aizawa 2007; Rupert 2004; Wilson 2014). Notably, the idea that our cognitive processes may extend beyond the boundaries of our nervous system leads to a series of issues that are nowadays classical in the literature, and which stand in the way of a coherent story about the possibility of an extended mind. Among such issues, there is that of understanding how the cognitive process of a certain agent can extend to parts of the environment that are not always and permanently linked (also considering the numerous problematic ways in which such a link might occur) to her own natural body. Indeed, among the remarkable consequences of EEC, one is that our own cognitive processes can be instantiated also in physical objects located far from our own bodies, such as the books in a library or even a distinct and different person's body part.

The big issue here is that the external states are not persistently coupled with the agent's body, unlike those that are internally based. An intuitive solution could be that some external extension is fortuitously broken so that the integrity of the cognitive system is lost and can be eventually re-instantiated only once the coupling with this state is recovered. Now, since it is mostly unobvious to think of a cognitive system as something scattered in the environment, someone may be inclined to consider EEC an implausible version of ECT. Though defenders of ECT replied to this and similar challenges many times (e.g., Clark 2010a; Menary 2010; Wilson 2014), EEC is still considered a controversial conclusion.

Interestingly, over the past decades, little attention has been addressed to the fact that ECT can, in principle, also entail IEC, namely the claim that cognition extends to physical realizers that are located outside of the nervous system (anatomically intended), but within the agent's body.

Our goal is precisely that of providing the first example of this 'internal extension'. In order to do so, we will discuss empirical evidence that will serve as a basis for a philosophical argument in favor of IEC: we will focus on the functioning of the microbiota-gut-brain (MGB) axis, that is, on the activity of the human gut microbiota (GM), which constantly is in interaction with the human nervous system, carrying out genuine cognitive functions. 
The reader should note that the term 'microbiota' refers to the complex community of microorganisms (spanning from bacteria to viruses) which live in and on humans and other organisms (commonly labeled as 'hosts'). ${ }^{2}$ The most famous one is GM, which populates the intestines. However, various crucial areas of the body (such as lungs, oral cavities, the skin, etc.) are inhabited by associated microorganisms as well (Belkaid and Hand 2014). Several studies have suggested that the relationship between the microbiota and humans is not merely that of a non-harmful either commensal or parasitic coexistence, but rather that of a valuable functional relationship (Gilbert et al. 2012; Bordenstein and Theis 2015). In other words, microorganisms in the agent's gut perform particular causal roles that deserve further investigation.

Notably, recent evidence about the activity of the MGB functional axis has suggested that specific cognitive functions, which have been always ascribed only to the functioning of the nervous system, are shaped also by direct and indirect activities (from biochemical to ecological ones) of the microorganisms that inhabit what we macroscopically call "our body" (Archie and Theis 2011; Fetissov 2017; Johnson and Foster 2018a, b; Valles-Colomer et al. 2019).

For example, there is growing evidence suggesting that alteration of the composition of gut microbiota can impact on a wide range of neurotransmitters, including dopamine, norepinephrine, serotonin, and gamma-aminobutyric acid (Buffington et al. 2016; Strandwitz 2018). This evidence allows one to hypothesize that the manipulation of these neurotransmitters by bacteria may have an impact on different aspects of the host's behavior by affecting the related cognitive functions (Johnson and Foster 2018a, b). Notably, though the mere production of neurotransmitters by GM is not conclusive proof that GM has an influence on the host's cognitive activity, it should be also considered that there is preliminary evidence that the neurotransmitters produced by GM actually reach the central nervous system, exerting a causal role on it (Kiraly et al. 2016; O'Donnell et al. 2020; Strandwitz 2018). Our argument that cognition extends to the activity of GM relies on such encouraging results and on the optimistic, although quite reasonable, assumption that further evidence will confirm the available data. At present, a growing amount of experimental research supports this hypothesis, suggesting that the activity of the gut microbiota has a causal effect on central cognitive functions, such as those underlying emotions, decisions, and memory (for a detailed review, see "Discovering the impact on cognitive function by the Gut Microbiota" section).

The focus on the functional aspect is crucial. In this respect, it is important to recall how the MGB axis should be intended as profound and plural bidirectional crosstalk among different organs' activities through the mediation of microbiota rather than a precise, well-defined anatomic structure. As already mentioned, it has also been argued that the functioning of GM, due to its ecological relationship with the host, is dependent on events occurring in the nervous system, which reinforces a two-way functional role along the MGB axis. Indeed, while the activity of GM

\footnotetext{
${ }^{2}$ However, we will show that this division can be somehow problematic in light of the most recent advancements of biological research.
} 
shapes the activity of the agent's nervous system, the activity of the nervous system affects that of GM (on the causal nature of this interaction see further "On causality" and "'Microbiota-host relationship: beyond symbiosis and the holobiontic perspective" sections).

The aim of the paper, whose argument draws on these experimental discoveries, is twofold. First, we show that, if this evidence is confirmed, there are enough empirical arguments to claim that GM has a genuine cognitive role in shaping several aspects of the agent's behavior. ${ }^{3}$ Second, if so, as we shall argue, the MGB system should be considered as a physical realizer of our 'internally extended' cognitive system.

From an evolutionary perspective, more and more recent evidence supports the idea that both sides of the MGB axis have evolved and been developed in connection $^{4}$ (Rook et al. 2017; Foster et al. 2017a, b), so that their functional interaction is required for the accomplishment of specific cognitive functions. Indeed, recent studies suggest also that many kinds of symbiotic interactions might be seen and modeled as results of coevolution and thus should be functionally investigated under a common perspective (Huitzil et al. 2018). To this extent, the series of processes that are usually ascribed to the exclusive work of the brain can be considered as extending outside the 'boundaries of our skull', involving also the causal events that characterize the interaction between the human gut, its community of microbiota and the nervous apparatus.

Not only does our account of IEC suggest a new way of considering cognitive processes extended outside the brain, but extending the vehicle of our cognitive functions to the MGB system also proves very philosophically fruitful. The crucial benefit of the present account, indeed, is that it can propose an extension of cognitive functions that, however, does not suffer from the same issues that are traditionally addressed to EEC. Indeed, since, as we will show, the microbiota can legitimately

\footnotetext{
3 At this point someone may argue that our claim can be falsified by the fact that also germ-free agents show cognitive abilities, and therefore GM does not exert any cognitive function. However, it should be noted that, the fact that the microbiome performs a particular cognitive function does not mean that "only the microbiome" can perform that function. Functional studies show that microbiome activity plays a causal role in cognitive processing (see "Discovering the impact on cognitive function by the Gut Microbiota" section), but this does not imply that other ways of performing those cognitive functions are not possible or that germ-free agents are not cognitive agents. The scientific literature is full of examples in which cognitive functions "normally" carried out in a particular area of the cerebral cortex, given specific circumstances, are carried out in a different area. Such phenomena of plasticity and neural remapping are nowadays well known, and allow one to maintain that a certain function can change its vehicle depending on the circumstances. For example, in cases of stroke, recovery mechanisms are based on structural and functional changes in brain circuits that have a close functional relationship to those circuits affected by stroke, so that the function previously performed by a damaged area is subsequently performed by another different area (Murphy and Corbett 2009). Moreover, the literature is nowadays consistent in assuming that blind agents can perform explorative functions, usually performed by means of vision, by exploiting different cognitive resources (Bach-y-Rita 1967; Noë 2004). Thing being so, cases in which agents are deprived of their GM are not a problem for our thesis: though GM normally exerts a functional role in cognition, the same function can be exerted by other parts of the organism in particular circumstances. We thank an anonymous reviewer for having raised this issue.

4 This is true also for other cases, such as microbiota and the immune system (see for instance Belkaid and Hand 2014).
} 
be considered a proper extension of our digestive apparatus, and since the digestive apparatus is part of our physical body, IEC does not present the counterintuitive consequence of scattering the cognitive agent outside the boundaries of the agent's skin, through the environment.

Our argument proceeds as follows. We first introduce experimental evidence suggesting that the functional activity of the MGB axis plays a crucial role in allowing the agent to accomplish specific cognitive tasks ("Discovering the impact on cognitive function by the Gut Microbiota" section). Then, we argue that there are reasons to consider GM as a functional part of our organism, rather than a mere symbiotic system ("Microbiota-host relationship: beyond symbiosis and the holobiontic perspective" section). At this point, on the basis of further empirical evidence and conceptual analysis, we argue that the functioning of the MGB axis represents a good candidate in order to empirically support IEC ("The gut microbiome as an internally extended cognitive vehicle" section). Finally, we show that our argument in favor of IEC is also capable of facing the main issues that are usually raised against ECT ("Possible worries and replies" section). We also offer some concluding remarks on the fact that our cognitive processes are not entirely realized by the activity of 'our brain', but rather extend beyond the boundaries of 'our skull', though within 'our skin'.

\section{Discovering the impact on cognitive function by the Gut Microbiota}

GM is an association made of a huge number of bacteria (approx. $10^{14}$ ), and for this reason, it is considered one of the most densely-packed ecosystems we know (Gilbert et al. 2018). The composition of GM is mainly dominated by the phyla of Bacteroidetes and Firmicutes, although more than a thousand different species have been reported in human adults (Qin et al. 2010). Each individual is characterized by a specific proportion of various species and strains that constitutes her own 'microbial fingerprint' (Calvani et al. 2018). Despite this internal diversity, GM is quite stable in individual adults, and displays a consistent functional capacity among healthy persons, unless disturbance factors occur. Nevertheless, a significant variance has been observed among different individuals, so that configurations of GM influencing a 'healthy state', may be different from one subject to another (Lozupone et al. 2012; The Human Microbiome Project Consortium et al. 2012).

This section highlights the cognitive role of GM, which figures among the most striking discoveries of this decade. While interactions between the central nervous system and the gastrointestinal tract having been qualitatively recognized for many centuries, it was only in the nineteenth and early twentieth centuries that this relation was seriously assessed by physiologists and psychologists. The availability of new tools suitable to reveal the bi-directional interactions between gut physiology and nervous functions had an important role, opening new frontiers of research about the impact of GM on individual cognitive processes and behavior. Nowadays, links between the central nervous system and GM are well-known and remain one of the hottest topics of scientific research of medical interest, challenging some of 
the standard views in medicine and cognitive sciences (see for instance Editorial, Nature 2019, Feb; 566-7742).

Of crucial relevance for this paper, evidence suggests that the multifaceted communication between the gut and the central nervous system not only is apt to ensure the maintenance of gastrointestinal and digestive functions but also allows the gut to exert effects on emotional behavior and higher cognitive processes by means of variations in the composition and activities of GM. The relations between GM on the one hand, and emotional and cognitive functions, on the other hand, are made possible through multiple interactions, such as the existence of bi-directional neural pathways, neuroendocrine signaling, as well as the role of the immune system (Carabotti et al. 2015; Grenham et al. 2011; Mayer et al. 2014).

But how can GM exert its extra-intestinal influence? And, in this respect, how can GM be relevant for cognitive processing? The ways in which GM shapes aspects of cognitive functioning are addressed in the following subsections. We proceed by introducing basic physiological and functional evidence about the MGB axis, then we focus on its role in regulating the agent's behavior by means of influencing emotional cognition and performance in memory tasks.

\section{The Microbiota-Gut-Brain axis}

In recent years, advancements have been made in describing the bidirectional interactions between the central nervous system, the enteric nervous system, and the gastrointestinal tract. Indeed, a number of studies have suggested a central role for GM in these interactions, leading prominent scholars to coin the notion of the Microbiota-Gut-Brain axis (Lyte and Cryan 2014). The MGB axis refers to the system of biochemical signals that takes place between the gastrointestinal tract and the nervous system and is frequently used to highlight the extra-intestinal functions of GM. As previously mentioned, it is important to recall how this axis should not be intended as a well-defined anatomical trait or structure but rather as a functional descriptor. Thus, it is not literally an 'axis', but rather a way to stress the presence of a great variety of modes of interactions between the gut, the brain, and microbiota.

Thus, broadly defined, the MGB axis includes the central nervous system, the neuro-immune systems, the sympathetic and parasympathetic systems, and GM. Notably, the nervous system signals to the gastrointestinal tract through a large network of neural, hormonal, and immunological routes (e.g., the sympathoadrenal axis and hypothalamic-pituitary-adrenal axis, the monoaminergic pathways). Inside the brain, signals from the gastrointestinal tract reach the hypothalamus and the amygdala which, in turn, receive inputs from a number of higher associative areas, including prefrontal cortex and cingulate cortex (Al Omran and Aziz 2014; Ongür and Price 2000).

Furthermore, the vagus nerve has been shown to serve as a prominent route for the interactions between the gut and the brain (Forsythe et al. 2014; Forsythe and Kunze 2013). This stream may represent a bidirectional functional pathway, spanning from the gastrointestinal tract to the central nervous system and back to the sympathetic part of the autonomic nervous system, which is implicated in the 
immune regulation and homeostasis of the gut (Foster et al. 2017a, b; Perez-Burgos et al. 2014).

Recently, a great interest has been addressed toward the peculiar role of GM in regulating the gut-brain interactions (e.g., Kelly et al. 2017; Sharon et al. 2016). For example, it has been suggested that GM may modulate the synthesis of a number of neurotransmitters, including serotonin, dopamine, noradrenaline, and gamma-aminobutyric acid, which function as mediators between the activities of GM and the nervous system (e.g., Sarkar et al. 2016; Yano et al. 2015). Notably, through multiple pathways, GM may exert an extensive influence on key neurological and behavioral processes also in critical phases of early neurodevelopment and senile neurodegeneration (Dinan and Cryan 2017; Sharon et al. 2016). During early-life, GM plays a role in shaping the organization of neuronal networks influencing social and emotional domains of cognition (Kelly et al. 2017; Sharon et al. 2016). For example, animal studies have reported that antibiotic administration during the first year of life is correlated with depression and behavioral difficulties later in life (Slykerman et al. 2017). The administration of antibiotics postnatally changes the physiological status of the offspring in animal models and subsequently modulates its affective behavior. Moreover, though aging reductions in GM are usually associated with a reduction in microbial complexity, specific alterations and increased diversity in GM composition, structure, and function have been retrieved in individuals with neurodegenerative pathologies (often associated with aging) such as Alzheimer's disease and Parkinson's disease (e.g., Jiang et al. 2017; Scheperjans et al. 2015). Alzheimer's disease $(\mathrm{AD})$ is the most frequent cause of dementia characterized by a progressive decline in cognitive function associated with the formation of amyloid-beta plaques. A growing body of experimental and clinical data in mice and humans supports the hypothesis that so-called GM dysbiosis ${ }^{5}$ exerts a key role in neurodegeneration and formation of amyloid-beta plaques, together with aging and other environmental factors (Kowalski and Mulak 2019).

The above-mentioned studies indicate a close connection between microbiota and behavior and suggest the presence of functional pathways through which they interact. By taking a look at this assembly of morphological and functional evidence, it is nowadays possible to appreciate the general principles regulating the extra-intestinal influence of GM. A way to address this issue is to conceive the functions exerted by microbial communities, either directly via metabolites or indirectly via the immune and endocrine systems, as providing the nervous system with information concerning the environment.

Interestingly, studies have shown how the nervous system (alone or together with the immune system) can influence microbial activities and composition. Indeed, as already mentioned, the MGB axis constitutes a bidirectional scenario. Several studies (e.g., Lyte and Cryan 2014; Zhao et al. 2018, Li et al. 2020) have highlighted the reciprocity of the MGB axis, by considering how much the brain acts on the gut,

\footnotetext{
5 On this notion and its problems, see ("Microbiota-host relationship: beyond symbiosis and the holobiontic perspective" section).
} 
through multiple neural, hormonal, and immunological pathways. ${ }^{6}$ First of all, the brain can affect the activities and composition of the microbiota indirectly, acting on gut motility, modulating secretions, and regulating visceral permeability. Furthermore, the brain can also act directly, through chemical-molecular signals, conveyed by certain types of cells (such as, among others, neurons), in the intestinal lumen (Rhee et al. 2009). Moreover, recent findings, due to a more profound understanding of the relations between the central nervous system (CNS) and the enteric nervous system (ENS), have revealed how the nervous system (as such) is deeply involved in shaping the gut ecosystem and thus microbial activities (Yoo and Mazmanian 2017). These aspects become particularly crucial when specific pathologies (presenting both neurological and metabolic aspects), such as obesity, are addressed since they might offer a basis for new therapeutic approaches (see Agustí et al. 2018; Niccolai et al. 2019). In addition, it has been recently reported that brain injuries can affect microbiota both in functionality and composition (Houlden et al. 2016). Furthermore, all these aspects, underlining the bidirectionality of the relationships between the microbiota and the brain, can very well serve to support the 'holobiontic perspective' (see "Microbiota-host relationship: beyond symbiosis and the holobiontic perspective" section).

Therefore, determining how GM changes with respect to environmental factors, and how this shows, in turn, an impact on the processing that underlies behavior (and vice versa), represents a fascinating challenge at the intersection between biomedical research, microbial ecology, and the cognitive sciences.

In this section, we mentioned only some preliminary physiological and functional experimental results about the MGB axis. In doing so, we paved the way for the experimental framework we use in order to defend our philosophical claim. In the next two sections, we put forward a cognitive approach to the MGB axis, focusing on some functions of GM. To this aim, we first focus on two different sets of evidence that may help to explain the role of GM in shaping specific cognitive processes. Then, we discuss a way to interpret such a role in terms of cognitive processing. This will constitute the crucial evidence at the basis of our philosophical claim.

\section{The MGB axis and emotional processing}

One of the most intriguing areas of investigation concerning the cognitive functions of the MGB axis is represented by the role of GM in shaping emotional behavior, particularly in anxiety and depression (Foster and McVey Neufeld 2013). Interestingly, it was precisely the discovery of a correlation between stress, anxiety, and the alternation of GM that alerted scholars to the possibility of bacterial involvement in psychological processes (Sarkar et al. 2018).

Before introducing the evidence suggesting the functional role of GM in the processing of emotions, it should be noted that emotions are nowadays considered as cognitive states that are essential to rational thinking and normal social behavior.

\footnotetext{
${ }^{6}$ Among these ones, it is worth mentioning both the sympathetic-adrenal system and the so-called hypothalamic-pituitary-adrenal axis (or HPA).
} 
Importantly, though for a long time emotions have been disregarded as mere reactions to environmental stimuli, several theoretical and empirical works have contributed to changing this paradigm, fostering the idea that processing emotional states is crucial for a plethora of cognitive activities. Emotions, indeed, determine how an individual perceives the world, organizes memories, and makes pertinent decisions (e.g., Damasio 2005; Oatley and Johnson-Laird 2014; Okon-Singer et al. 2015; Pessoa 2008; Prinz 2006; Storbeck and Clore 2007).

Over the years, most of the research on the psychological effects of GM has focused on rodents' behavior, representing a first step toward the understanding of this phenomenon. Notably, researchers have clustered largely around negative emotional states and their behavioral manifestations. For example, emotional states related to stress and anxiety, such as fear and depression, are inferred from the time spent by the rodent to explore new and unfamiliar environments. This measure is considered a key behavioral feature of approach and orientation and is usually relevant as the agent adapts to novel situations, such as being at the center of a maze. Thus, alterations in time spent in exploration can be considered as revealing the occurrence of negative emotional states (Sarkar et al. 2018; Walf and Frye 2007).

Now, a growing body of evidence suggests an important influence of GM on emotional behavior and underlying brain mechanisms. Recent experiments revealed an anxiolytic-like behavior in germ-free rodents, compared to control rodents (Neufeld et al. 2011). Importantly, such a difference is not found in vagotimized agents, suggesting a functional role for the MGB axis in emotional processing (Bravo et al. 2011).

Interestingly, Bercik et al. (2011) have shown that transferring fecal content from an innately stress-sensitive mouse to non-anxious mice is sufficient to elicit anxiety-like reactions (i.e., reduced exploratory behavior) in the receiver animal. Correspondingly, the reverse pattern, that is, transferring portions of GM from non-anxious mice to innately anxious mice induces the latter to manifest reduced anxiety (for an analogous result, see also the more recent Chevalier et al. 2020).

For the sake of our argument, it is interesting to note that recent investigations have suggested that germ-free rodents display specific impairments in maintaining the associations involved in manifesting normal fear behavior, showing reduced reactions in response to contextual cues related to noxious stimuli (Hoban et al. 2018). Scholars found that, after training, germ-free animals displayed reduced freezing to conditioned stimuli associated with possible pain. Crucially, this evidence suggests that GM is a functional component involved in the normal development of fear-learning processes (Sarkar et al. 2018). Indeed, this altered behavioral profile can be mitigated by the successive recolonization of the rodent's gut with a conventional GM.

Remarkably, this concept has also been expanded to humans. Healthy volunteers that consumed milk containing different probiotic bacteria, which affected the equilibrium of their GM, showed altered cortical activations during the execution of an emotional faces attention task, as measured with fMRI studies (Tillisch et al. 2013). The authors administered a probiotic mixture to female participants over several weeks, and then participants viewed emotional stimuli (faces) while undergoing functional magnetic resonance imaging. As a result, with respect to controls, 
participants showed reduced activation in brain regions that are known to be functionally implicated in the processing of emotional information, including the insula and the somatosensory cortex. This suggests that an alteration of the MGB axis may have an impact on human emotional experience as well.

In another study, Tillisch et al. (2017) using fecal samples, magnetic resonance imaging (MRI), and an emotion induction task, assessed the relationship between GM composition in healthy women and the characteristics of brain structure and brain function as measured by affective response to emotionally related images., The authors found a correlation between the genetic profile of microbial clusters and the hippocampal activity related to the emotional experience of the subjects. This evidence suggests that the composition of the bacteria community inhabiting the agent's gut has a functional impact on the processing of emotional stimuli in humans.

Furthermore, Bagga et al. (2018) performed a placebo-controlled randomized study aiming at investigating the effects of the administration of probiotics on emotionally driven behavior and brain activation. In this experiment, forty-five healthy participants divided into three groups (probiotic, placebo, and no intervention) were asked to perform emotional decision-making and emotional recognition memory tasks while scanned with functional MRI. Interestingly, human subjects administered with probiotics showed changes in brain activation patterns in response to emotional memory and emotional decision-making tasks.

To summarize, although most of our understanding of the emotional interaction between the microbiota and the brain has come from rodent models, in which the gut microbiota is linked to brain signaling mechanisms and affective behavioral phenotypes, there is encouraging evidence concerning the causal relationship between gut microbial community structure, brain structure and emotional processing in humans. Although this is not conclusive, the reported evidence allows us to hypothesize that GM plays a key role in the processing of emotions both in non-human and human agents, interacting closely with other brain structures involved in this function.

\section{The MGB axis, memory, and behavioral control}

Over recent years, an increasing amount of empirical research has suggested that the rate of success in executing tasks involving higher cognitive abilities may be related to the conditions of the agent's GM (Novotný et al. 2019, Sanguinetti et al. 2019). Interestingly, studies on rodents have found significant effects of GM alteration on cognitive processes guiding behavior, such as learning and memory. For example, the experimental research has shown the effects of either gut infection or absence of GM in rodents, particularly on non-spatial memory behavior, showing that memory dysfunctions occur in infected mice exposed to acute stress, while the germ-free agents' memory abilities are altered at baseline. Early evidence of the functional relationship between GM and higher cognitive abilities is related to the impairment of hippocampal activity and memory functions in germ-free mice as compared to normally colonized rodents (Gareau et al. 2011). Successive studies have found that 
exposure to antibiotics temporarily impairs learning and memory performance in mice (Wang et al. 2015).

Interestingly, further research has suggested associations between GM and cognition in human adults as well. Studies on obese individuals, for example, provide evidence of a correlation between GM composition and the agent's performance in executing tasks involving attention and cognitive flexibility (Sarkar et al. 2018). Notably, GM influences host dietary behavior, regulating satiety, and energy intake (Fetissov 2017; Frost et al. 2014). Again, evidence of this function is illustrated by obesity, which in both mice and humans is associated with an alteration of GM composition, inducing a bacterial-dependent capacity of extracting energy from food, which in turn affect the agent's disposition to select and ingest specific aliments (Agustí et al. 2018; Ley et al. 2006). Importantly, evidence such as this suggests that GM has a role in orienting the behavior of the agent, contributing to select specific types of interactions with the environment, like the goal of ingesting particular categories of food rather than others. In this respect, it can be said that GM performs a function similar to that of other cognitive mechanisms regulating food intake, which are classically located within the boundaries of the nervous system (e.g., the hypothalamus, see Cazettes et al. 2011). Consequently, even if the causal web of these phenomena is far from being fully understood, growing evidence allows one to consider the fruitful hypothesis according to which GM has a cognitive function in shaping the agent's alimentary behavior.

Moreover, there is evidence that greater diversity in GM (composition and population interactions) is related to variation in the microstructures of brain areas, including those functionally connected to learning and memory tasks (FernandezReal et al. 2015). Studies in infants found that a greater GM diversity impacts exploratory and communicative behaviors and cognitive performances (Carlson et al. 2018). Interestingly, results suggest that higher levels of diversity are not always correlated with cognitive improvements, but also with lower performances. Nonetheless, findings of this sort highlight the function of the MGB axis in human cognition, stimulating new research on the regulating role of GM (see Sanguinetti et al. 2019).

Importantly, also several indirect results point toward the cognitive role of GM. For example, patients suffering from Irritable Bowel Syndrome (IBS), i.e. a functional gastrointestinal disorder associated with an altered GM (and possibly alterations of the MGB axis), display an increased recognition memory concerning words with a negative emotional connotation in contrast to either healthy controls or patients with different gastrointestinal diseases (Gareau 2014; Ringel and Maharshak 2013). Related to this effect, Gibbs-Gallagher et al. (2001) have shown that patients with IBS have difficulties in recalling words and phrases concerning gastrointestinal symptoms, while they do not show the same difficulty in recalling phrases and words associated with respiratory symptoms. Evidence such as this supports the hypothesis that IBS impacts on the agent's cognitive functions subserving attention and behavioral responses.

Furthermore, an important role in this research area is played by the correlations between cognitive pathologies, the composition, and the activity of the agent's GM. In a recent review published in Science, Sherwin et al. (2019) have collected 
evidence suggesting an important role of the microbiota in disorders of social behavior in both non-humans and humans. For example, the authors have reported that the analysis of the fecal microbiota of children with autism spectrum disorder (ASD), which involves an impairment of normal social behavior, shows a strong alteration in the composition of GM, with peculiar losses in key bacterial taxa along with the presence of harmful strains, frequently associated with gastrointestinal pathologies (Finegold, 2011; Góra et al. 2018; Son et al. 2015). Though such evidence needs further discussion and confirmation, it nevertheless suggests the hypothesis according to which GM has a functional role in regulating the cognitive activity involved in high-level processes such as those underlying social behavior.

Before concluding this section, if the reader were not convinced about the deep impact of GM on cognitive functions, it is noteworthy that variation in GM composition has been associated also with the manifestation of mental disorders consisting of highly distorted contact with reality. More precisely, several common classes of antibiotics used for the treatment of various infections, whose lethal effect on GM is known, have been recognized also to induce non-permanent psychosis in certain patients. Among the most common antibiotics known to have psychotic inducing effects are, for example, penicillin, quinolones, macrolides, and anti-tuberculosis agents (Cummings et al. 1986; Kass and Shandera 2010; McCue and Zandt 1991). Symptoms develop within the first days of treatment and include visual and auditory hallucinations, loss of orientation, space and time delusions, and agitation. For the sake of the present argument, it is interesting to note that antibiotic-induced changes in GM also induce changes in brain chemistry and behavior. Bercik and Collins (2014) have shown that an intraperitoneal administration of antibiotics failed to show an impact on the behavior of rodents, while the oral administration of the same antibiotic mixture has relevant behavioral consequences. The authors interpreted this finding to mean that the altered GM profile was responsible for the changes in behavior by means of effects on the hippocampus and the amygdala mediated by the MGB axis.

Recently, an increasing number of scholars have started to investigate how microbiota can improve drug discovery for psychiatric and behavioral disorders, launching the idea that in the future the term 'psychobiome' could represent a solid area of scientific inquiry and not just a fancy speculative term (Pennisi 2020). For instance, some researchers (Valles-Colomer et al. 2019) have shown that the number of bacteria belonging to genera Coprococcus and Dialister, was diminished in patients with depression. Moreover, they also confirmed a positive correlation between quality of life and the capacity of some bacterial strains "to synthesize a breakdown product of the neurotransmitter dopamine, called 3,4-dihydroxyphenylacetic acid. The results are some of the strongest yet to show that a person's microbiota can influence their mental health" (Editorial, Nature 2019, Feb; 566-7742). Other groups revealed that diverse bacterial strains can modulate, produce, and consume neurotransmitter inhibitors, such as GABA (Strandwitz et al. 2019). In addition to that, another venue of studies has started to accumulate evidence supporting the view that microbiota can be implicated in the evolution of social behavior in complex social eukaryotes (including humans) and in the functional development of the structures allowing it (Sherwin et al. 2019). 
As already mentioned, one crucial issue of many studies concerning the impact of microbiota on cognitive functions depends on the fact that most of them show interesting correlations but a mechanistic understanding is yet to come. Therefore, before going on with our proposal, it is necessary to spend some words on the causal aspects concerning this area of scientific investigation.

\section{On causality}

A fil rouge of this work is the notion that the microbiota, being a crucial component of a network of symbiotic relationships, is at the center of causal connections that, first, involve different populations of microorganisms and, second, the other component, the 'host'. This has prompted much host-microbiota research to postulate the presence of a causal dependence for a variety of phenomena, in both physiology and behavior, concerning the human being. According to recent work (Lynch et al. 2019), many studies that support a causal role of the microbiota in phenomena concerning the physiology of the host organism seem not to respect crucial epistemic conditions for 'causality'. This possibility could, at first glance, constitute an objection to the thesis presented here. However, we believe this is not the case. Although we do not have space here to go into the details of the general debate about causality, to clarify our line of thought, we believe that some points need to be addressed.

First of all, given the systemic nature of the object of our analysis (the microbiota-host relationship), we believe that the accounts of causality examined in the criticism (e.g. interventionist causal framework) may not be the most suitable for the situation. In particular, as recently argued (Lean 2019; Klassen 2019), microbiota, in its ecological dimension, can have a causal influence on higher, systemic properties. The recent attempts to influence, and experimentally intervene on microbiota according to new manipulation criteria derived from disciplines other than molecular sciences, such as ecology (Boem et al. 2020), also go in this direction. Moreover, the adoption of the so-called 'holobiontic perspective' (see on this "Microbiota-host relationship: beyond symbiosis and the holobiontic perspective" section), makes this possibility even more established and concrete.

Secondly, from the point of view of cognitive sciences, there is currently no single causal account shared by the scientific community, but rather a plethora of hypotheses on causality that compete on empirical ground. For our purposes, in relation to cognitive sciences literature, it is evident that the microbiota can be seen as a 'difference maker', concerning the determination of some crucial cognitive functions, even if the mechanistic description of these interactions is still partially incomplete.

Finally, our argument, in fact, explores a theoretical possibility: if the empirical evidence examined is to be considered solid, then there are good reasons to argue that the activity of the microbiota constitutes a legitimate extension of cognitive functions.

In what follows, we offer an innovative account of extended cognition, according to which it can be seen as being realized outside the brain, but still inside the body. This is what we call the 'Internally Extended Cognition Thesis'. We believe that not only our thesis but also our approach for defending it is innovative, as the argument 
we offer is supported by recent empirical findings in the life sciences and biomedicine, which suggest that the gut microbiota's activity might have a functional role in regulating our cognitive processes and behaviors.

Our opinion is that these sets of evidence would be better framed in light of the so-called holobiontic-perspective. According to this view, what we call biological individuals are not autonomous entities with clear boundaries, but should rather be seen as networks of multiple species interactions (see "Microbiota-host relationship: beyond symbiosis and the holobiontic perspective" section). Consequently, we argue that gut microbiota could be seen as a component of our organism (Bordenstein and Theis 2015). On this basis, we claim that gut microbiota can be plausibly seen as a functional part of our cognitive system. However, if that is the case, this requires us to extend cognition out of the agent's skull, though still restricting it within other internal parts of the organismic agent: its own gut.

\section{Microbiota-host relationship: beyond symbiosis and the holobiontic perspective}

Traditionally, a relationship of association (either being commensal, mutual, or parasitic) between diverse biological species (such as animals and plants with bacteria or fungi) has been labeled as symbiosis. Members of these associations are thus called symbionts. Virtually, anything we perceive and define as an organism is the result of symbiotic activities. This is quite evident for macroscopic living beings (such as the vast majority of animals and plants) (Suárez 2018a, b) but also for other forms of life (e.g. the origin of mitochondria) (Roger et al. 2017). Symbiosis is a widespread phenomenon, intertwined with both empirical issues (e.g. speciation and evolution) and theoretical ones (e.g. biological individuality). Famously, Lynn Margulis argued that symbiosis should be regarded as a key factor in evolution (maybe even the key factor), challenging our vertically-based conception of phylogeny and suggesting the centrality of this phenomenon for the origin of eukaryotic cells (Corliss and Margulis 1972). Moreover, there is mounting evidence suggesting the crucial role of symbiosis also for physiology (Rook et al. 2017), for speciation (S. F. Gilbert 2019; S. F. Gilbert et al. 2012), and phylogeny (Brooks et al. 2017). ${ }^{7}$

A typical symbiotic relationship is the one constituted by humans and their associated microorganism, what is better known (as already mentioned) as the microbiota. Data concerning this symbiotic relationship are fascinating. Different microbial cells extensively inhabit the so-called 'human body', spanning from the gut to the mucosa, including genitals, lungs, and skin (each of these generating specific niches and possibly sub-niches). Associated microorganisms are thought to be as abundant as human cells (or even more) and, as matter of fact, the global bacterial genomic activity greatly surpasses its human counterpart (Gilbert et al. 2018).

\footnotetext{
7 Interestingly, the authors propose the fascinating term of 'phylosymbiosis' to describe the "eco-evolutionary pattern, whereby the ecological relatedness of host-associated microbial communities parallels the phylogeny of related host species" (Brooks et al. 2017, p.1).
} 
Moreover, bacteria are divided into a huge variety of species and strains ${ }^{8}$ enhancing the chance of genetic diversity and plasticity more than traditional single-organismbased genetics (Gilbert et al., 2018), not to mention that these data do not include viruses and fungi.

This situation also presents strong implications for the current understanding of both physiological and pathological conditions of humans. Indeed, growing evidence suggests that several kinds of imbalance in the composition and/or functionality of the microbiota (usually addressed by the umbrella term 'dysbiosis'), might show a deep impact on the host's health, suggesting how crucial the presence and the activity of the microbiota is in order to understand phenomena previously ascribed 'just to the host' (Belkaid and Hand 2014; Amedei and Boem 2018). Nonetheless, the complexity of these phenomena is far from being unraveled and the term 'dysbiosis' as such still leaves unsolved many aspects of the matter. Thus, in order to establish 'healthy forms' in the microbiota's composition (in terms of types and magnitudes of both populations and species) more work is required, also to better frame these findings into a more robust ecological and evolutionary perspective (see Hooks and O’Malley 2017; Brüssow 2020).

Nevertheless, despite this empirical progress, symbiosis still tended to be traditionally conceived as a relationship, although complex, among discrete and autonomous biological entities. In recent years, this view has been progressively challenged at its core. Indeed, Bordenstein and Theis (2015) have recently argued in favor of a conceptual shift, claiming that macroscopic organisms (such as the ones we usually call 'animals' or 'plants') should no longer be considered as independent, autonomous entities. Alternatively, they should be seen as "biomolecular networks composed of the host plus its associated microbes, i.e., "holobionts"" (Ibid. p.1). Accordingly, what we normally call 'organisms' may rather be seen as collections of interconnected biomes which form, in various ways, still not entirely understood, integrated functional wholes or holobionts. Indeed, following standard scientific categorizations, holobionts can be described as aggregations of several species, usually composed of a macroscopic 'host' and its associated 'microbiota' (which can include not just bacteria but also fungi and viruses) in a symbiotic relationship. However, this does not prevent us from adopting a new perspective on holobionts, privileging their status as 'units' and thus challenging the traditional categories defining this kind of relationship.

In light of all we have been saying, the notion of holobiont has the potential to change both concepts of symbiosis and organism and to extend them. In other words, while previous accounts were based on the idea that symbiotic associations occurred among distinct biological individuals, this new perspective aims to reconstruct the notion of symbiosis on more ecological grounds, also suggesting a reframing of the notion of biological individual itself, and organism, beyond traditional genetic and immunological criteria (Rees et al. 2018).

Such a change should not be seen just in theory. In many research fields, such as, for example, immunology, the impact of microbiota in the training, maintenance,

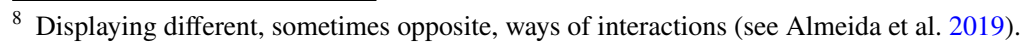


and efficacy of the immune response has led some scholars to argue that the very notion of the immune system should be revised in light of these findings (from a mainly defensive account to a broader systemic regulatory one), and microbiota itself should be considered a part of the immune functional system (Amedei and Boem 2018; Belkaid and Hand 2014; Eberl 2010). This could be seen as the immune system no longer being 'just human', at least from a genetic point of view. Instead, it could be better conceived as pertaining to the entire organismic 'functional whole', including GM as its proper part. Now, since the immune system is part of one's own bodily identity, and since GM can be considered part of it, GM should also be deemed as part of one's own bodily identity (on this point, see "Possible worries and replies" section). In order to appreciate this point, it is crucial to better specify what we mean by integrated functional wholes. First, we should briefly discuss the current debate concerning the notion of both organism and biological individual (see, for instance, Nicholson 2014). There is an ongoing heated discussion, in both biology and philosophy of biology, regarding what constitutes a biological individual (Hull 1978, 1980, 1992; Sober 1991; Wilson 1999, 2005; Gould and Lloyd 1999; Okasha 2006; Godfrey-Smith 2013; Clarke 2010; Pradeu 2012; Bouchard and Huneman 2013; Wilson and Barker 2016, Pradeu 2016). Moreover, there is also no complete agreement on whether or not individuals and organisms coincide, also leading to the discussion on whether these two notions can be considered as synonyms or not (Pradeu 2012, 2016). The literature on the topic is vast and deeply articulated. Nevertheless, we will set aside the debate about organisms, and better specify what we mean when we propose that holobionts might be seen as individuals. ${ }^{9}$ It is certainly true that seeing holobionts as biological individuals is not mandatory. Indeed, many scholars in the literature adopt this perspective while others claim that they are ecological communities composed of individuals (Suárez and Stencel 2020).

Nevertheless, it is crucial to recall that, in this respect, our perspective is mainly epistemic. Naturally, we are aware that the ways we define, delimit, and distinguish one individual from another, like any classificatory activity, have also ontological (even metaphysical) implications. However, here we are not interested in "carving nature at its joints", but rather in understanding how and why scientists and philosophers categorize their domains of inquiry the way they do (and how these activities produce what we call "knowledge"). In other words, we do not take a position on whether 'biological individuals' exist. Instead, we are concerned with their role in the construction of scientific explanations of crucial biological phenomena. Indeed, from the perspective of life sciences, it seems fundamental to have criteria to detect and discriminate certain units of organization of the living world, stable enough and cohesive to be considered the target of many events or processes, spanning from natural selection to therapeutic interventions.

\footnotetext{
9 This is also because, from a cognitive perspective, although we are sympathetic to the fact that cognition can be more rightfully conceived as "extended" within the individual (rather than segregated into just a single anatomic part such as the brain), we nevertheless grant that it should be the cognition of an individual, a somehow discrete part of the living world, anyway separable from the others and from the abiotic environment.
} 
Thus, epistemically speaking, following Pradeu's suggestions (2016), there might be several approaches to providing criteria to detect biological individuals. This means that, as just mentioned, leaving aside specific ontological commitments, scientists take specific perspectives to establish and delineate their object of inquiry, following either methodological constraints or heuristic protocols. Indeed, depending on the biological discipline, biological individuals can be seen, for instance, either as units of evolution or units of development. Just to provide some examples: genetics aims to grasp individuality by associating a 'unique signature' to the living, individual observable phenotype. On the other hand, both immunology and the neurosciences try to establish, although in different ways, the boundaries of the 'individual self'. Ecology, despite its focus on relations, does not necessarily avoid 'relata' (i.e. the more or less discrete units of these interactions). From this scenario, it is quite clear that many of these approaches are very different, as they literally point to different things (reflecting the explanatory interest of this or that discipline). Because of that, it should not surprise us that all these criteria can be conflicting, or at least they can produce/ point to several kinds of individuals.

Recently, Pradeu has advanced a more refined (grounded both philosophically and scientifically) approach to biological individuality based on certain features of a broadened view concerning the immune system (Pradeu 2012, 2016). Pradeu's idea (2016) is that immunology provides a good way to address a kind of biological individuality we are interested in since it grants uniqueness (the individual can be seen as a unitary whole), delineation (the individual has boundaries discriminating it from other individuals and from the abiotic context) and persistence (the individual is the 'same' individual through the flow of time).

Of course, all these features should not be understood as fixed or typological, but rather in a dynamic sense, as biological entities go through changes and modifications over their life cycle (think, for instance, of the phenomenon of metamorphosis occurring in insect development). Nevertheless, if we want to talk about individuals rather than simple 'biotic associations', we may want to have these properties.

On the other hand, it recently became evident that holobionts can be scientifically studied as such, i.e. multi-species collections constituted by the association of a macro-organism (traditionally called 'the host') and its symbiotic micro-organisms (Suárez and Stencel 2020). This means that, from a theoretical point of view, holobionts are now a genuine object of scientific inquiry. In other words, there are increasing studies approaching both experimentation and intervention, especially in the treatment of certain pathologies such as autoimmune diseases and cancer (Boem et al. 2020; Ronai et al. 2020) which address the holobiont in its capacity as a functional whole.

This entire perspective has important consequences for our tenets.

First, it shows that the holobiontic perspective challenges the idea that biological individuality necessarily implies autonomy and endogeny (thus, for instance presenting a homogeneous and isolated, even 'impermeable', cognitive makeup). On the contrary, living things are more 'porous', and both 'endogenous' and 'exogenous' elements can contribute to the creation of a quite stable individual whole. Indeed, this does not mean that certain kinds of living associations, i.e. biological 
individuals, cannot show a degree of unity that distinguishes them from other, more transient and contingent, forms of biological interactions.

Second, because of that, this perspective grants also the fact that our idea of extended cognition takes place within the boundaries of the entire individual body, although pertaining to the new conception of the individual, the holobiont. We believe that our proposal has the potential to challenge the entire lexicon of this research field since both extended cognition and embodied cognition are affected by this radical change of perspective.

Now, coming back to the main point of the paper, we would like to explain how these discoveries can be crucial for our speculations on the possibility of extended cognition. Indeed, we will show that, on the basis of the biological evidence concerning these discoveries, it is possible to claim that also the cognitive system can no longer be seen as 'just human'. Indeed, it should be understood as an internally extended system, which includes GM as its functional part. But if GM is part of the agent's cognitive system, and assuming that the cognitive system is part of the agent's bodily identity, we might speculate that even GM should be deemed part of the agent's bodily identity. Claiming this, of course, involves discovering the functional role of GM in cognition.

Things being so, on the assumption that future research will confirm the abovereported results, we are now able to introduce our philosophical claim concerning the internal extension of cognition: cognitive processes involve the functional interaction of the brain and GM through the MGB axis.

\section{The gut microbiome as an internally extended cognitive vehicle}

We can now use the evidence reported above ("Discovering the impact on cognitive function by the Gut Microbiota" section) and the conceptual notion of holobiont introduced ("Microbiota-host relationship: beyond symbiosis and the holobiontic perspective" section) to defend our philosophical claim. However, we have to go slowly on this.

First of all, we discussed the functions of GM in the agent's cognitive activity ("Discovering the impact on cognitive function by the Gut Microbiota" section), and then we considered the growing consensus in both experimental and theoretical biology about the need to reframe the biological notion of bodily identity beyond its traditional boundaries, and to consider an organism as constituted by a collection of interconnected biomes which form an integrated functional whole ("Microbiota-host relationship: beyond symbiosis and the holobiontic perspective" section).

On the basis of these empirical results and their conceptual interpretation, we maintained that, because of the functional role that GM exerts in cognition, it can be considered as part of the agent's cognitive system and, therefore, as part of the agent's individual identity.

In recent years, indeed, a growing body of extra-gastric implications of GM, in several non-digestive functions, has emerged. Despite cognitive functions being usually allocated within the activities of the central nervous system, as we have seen, today an increasing number of findings point toward the existence of massive gut-brain 
bidirectional functional interactions. Such interaction is made possible by the presence of what has been called the MGB axis, which includes a plethora of neural, hormonal, and immunological routes ("The Microbiota-Gut-Brain axis" section).

Among the several functions that are ascribed to GM, we focused on two cognitive factors guiding the agent's behavior, namely, emotion and memory. Concerning emotions, evidence strongly suggests that alteration of GM may have effects on nonhumans and humans, impacting on the agent's stress and fear-related behavior ("The MGB axis and emotional processing" section). Concerning memory, evidence suggests that changes in the composition of GM affect the execution of memory tasks and may lead to manifest psychosis-related behavior ("The MGB axis, memory, and behavioral control" section). Evidence such as this provides strong support to the hypothesis that GM exerts a functional role in cognition. This, in turn, seems to challenge the classical brain-centered mainstream in the cognitive sciences (Baluška and Levin 2016).

Now, we can resume the two premises which constitute the main argument for the claim defended in this paper:

(1) GM exerts extra-cranial cognitive functions (as shown in "Discovering the impact on cognitive function by the Gut Microbiota" section);

(2) An agent's bodily identity is constituted by an integrated system of functional parts (as shown in "Microbiota-host relationship: beyond symbiosis and the holobiontic perspective" section);

In light of (1) and (2), we also maintain that:

(3) GM can be considered as a functional part of the integrated system that constitutes an agent's bodily identity;

Therefore, if we accept (2) and (3), we can conclude:

(4) Cognitive functions extend outside the skull through a functional part of the integrated system that constitutes an agent's bodily identity.

Remarkably, accepting (4) is tantamount to accept that our cognitive processes may extend out of our heads without exceeding the boundaries of our body and that the functional role of GM in shaping our cognitive activity is a case of IEC ("Introduction" section).

In other words, as we have already stated, we believe that if the empirical evidence examined is to be considered solid (and we think there are good chances it could be), then there are good reasons to argue that the activity of the microbiota constitutes a legitimate extension of cognitive functions.

In the next sections, we will provide further theoretical support for our idea that, since there is a clear functional role for GM in shaping our cognitive activity, this counts as a case of IEC. 


\section{Possible worries and replies}

There might be objections to the proposal that genuine cognitive functions extend outside the brain boundaries. In what follows, we offer a reply to those we consider the most relevant among them. Doing so provides the opportunity to further elucidate and clarify our proposal.

Notably, there are two main issues that are usually addressed toward any attempt to extend cognition outside the conventional borders of the brain and that apply to our proposal, at least prima facie. The first issue concerns how to distinguish between genuine cognitive functions and mere causal interactions. Let us call it the 'distinction problem' ("The distinction problem" section). The second issue concerns the informational nature of cognition and how to find informational content in something that is not part of the nervous system. Let us call it the 'information problem' ("The information problem" section). Now, we can analyze them in detail.

\section{The distinction problem}

The distinction problem concerns the specific conditions under which cognitive processes are implemented outside the boundaries of the agent's nervous system: if cognition extends beyond the agent's skull, a criterion is needed in order to distinguish genuine cognitive vehicles from non-cognitive ones so as to avoid undesirable cases of cognitive bloat (Adams and Aizawa 2007; Allen-Hermanson 2013; Clark 2010a, b, c; Ludwig 2015; Rupert 2004).

Such cases are those in which an "unwelcome explosion of potential dispositional beliefs" (Clark 2010b, p. 80) occurs as a consequence of considering cognition an unbounded functional process. For example, it is generally considered a detrimental consequence of EEC that cognitive vehicles extend through the volumes in a library only because one has access to that library. Similarly, in the case of IEC, it could be detrimental to consider some part of the agent's body, say the heart, as a vehicle of cognition only because it has a biological function in allowing cognitive activities. But then, why should we include the MGB axis among the vehicles of human cognition?

An answer to this question requires additional specifications concerning the type of coupling which leads to genuine cases of cognitive extension (Piredda 2017). Notably, Clark and Chalmers (1998, p. 17) have initially proposed three criteria to restrict the functional relations to those with cognitive importance. According to Clark and Chalmers, to be a genuine vehicle of cognition, a portion of a causal system must always be: (i) reliably invoked; (ii) directly available; (iii) available without difficulty.

These criteria, also known as 'glue and trust' (Clark 2010a), concern the individuation of any alleged cognitive vehicle and aim to avoid extending cognition to implausible external resources like a library. The volumes of a library, indeed, are not usually invoked as wholly reliable and are not directly or easily accessible at any time in any place. However, such criteria are not sufficient to prevent an extension to 
equally implausible internal resources, such as the agent's heart whose function is usually reliable, and directly and easily available. Therefore, in order to avoid these cases, a further specification concerning the type of function exerted by the extended cognitive vehicles is required.

Some functional interactions are characterized by what can be considered a sort of self-generated 'looping mechanism' (Clark 2010b; Hurley 2001), that is, a structure where the output of a portion of the process is used as an input by another portion of the same process, which, in turn, generates new output. Here the specific point is that the output that a portion of the process recycles as input is generated by the system itself in a continuous and fluent looping mechanism.

Consider, for example, the well-known cognitive cycle linking action execution, stimulus perception, and working memory: here the execution of one action has the consequence of modifying the sensory input, which, in turn, gives rise to the working memory processing that contributes to generating a subsequent action as an output (Baars and Franklin 2003; Madl et al. 2011). In this case, none of the single parts of the causal chain has an autonomous cognitive function. Rather, their cognitive importance depends on the instantiation of ongoing mutual interactions. Accordingly, the postulation of a single coupled system constituted by action execution, stimulus perception, and working memory, is necessary with respect to the explanation of their individual cognitive relevance, which we would otherwise be at a loss how to account for.

The above considerations are crucial for our argument, as they provide us with support for including the instantiation of a looping mechanism as a further criterion by means of which we can judge whether distinct components of a causal chain constitute an overall cognitive process. Importantly, this criterion helps to avoid worries about cognitive bloat, allowing us to distinguish genuine cognitive extensions from ordinary functional interactions (Palermos 2014).

Remarkably, the function of the MGB axis can be deemed as a paradigmatic case of a self-generated looping mechanism. Consider the execution of specific actions like the ingestion of food. According to the available evidence, the agent's dietary behavior may be functionally linked with the condition of the agent's GM, which, in turn, may be altered precisely by the agent's dietary habits (see, "The MGB axis, memory, and behavioral control" section). Accordingly, since the MGB axis can be considered as part of a self-generated looping mechanism linking GM, the nervous system, and the agent's dietary behavior, it can be considered as part of a genuine cognitive process. Moreover, we have also seen that the composition of GM can be altered by the agent's emotional conditions, such as those related to anxiety and depression, and that intervening on GM may, in turn, impact on the emotional processing (see "The MGB axis and emotional processing" section). In this case, we have evidence that the activity and composition of GM also has a causal impact on the cognitive processing of emotions (Tillisch et al. 2017), and that an alteration of normal emotive conditions, such as in cases of stress, may impact on the activity and composition of GM (Karl et al. 2018). Sets of evidence such as these support the hypothesis that a looping mechanism is in play between the processing of emotions and the activity of gut microbiota so that a variation on the former induces a variation on the latter and the other way around. 
Since the functional role of the agent's heart in cognition does not figure as part of a looping mechanism involving other cognitive functions, it cannot be considered as a genuine vehicle of cognition. Indeed, though the pumping-blood function of the heart has a causal role in allowing the cognitive activity of the organism, cognitive functions do not have the same causal impact on the function of the heart. In other words, while there is a mutual, bi-directional interaction between the cognitive function of the nervous system and the biochemical activity of GM, so that the former may alter the latter, there is not a mutual, bi-directional interaction between the pumping-blood function of the heart and the cognitive activity of the organism.

To resume, if we assume self-generated looping mechanisms, together with 'glue and trust', as criteria for distinguishing implausible candidates from genuine cognitive vehicles, there is no risk of cognitive bloat, and the distinction between cognitive and non-cognitive causal functions is not a problem any further. Accordingly, we can now address the other common worry that might affect our proposal that cognition internally extends to the MGB axis, namely, the information problem.

\section{The information problem}

The information problem concerns the distinctive assumption according to which cognition is the computational processing of the information conveyed by an agent's mental vehicles. This problem arises because, according to the representational theory of mind, which has inspired cognitive sciences for decades, for something to be part of a cognitive process it must be possible to consider it as the vehicle of information involved in a computational process. According to what has been named the orthodoxy of cognitive science (Adams and Aizawa 2001,2007), genuine cognitive processes involve non-derived representations, that is, content delivering vehicles whose informational content is assigned in virtue of naturalistic conditions, independently of other representational capacities (Dretske 1995; Fodor 1990; Millikan 2009; Nanay 2014; Neander 2017). Now, because all the most common theories of non-derived representations find informational vehicles within the boundaries of the brain, it may seem prima facie reasonable to exclude the hypothesis that a genuine cognitive process can be constituted by something different from the brain itself (Adamas and Aizawa 2007; but see also Allen 2017; Adams and Garrison 2013).

In order to face this issue, two considerations concerning representational functions are needed. First, there is not any effective reason to state that external, nonbrain-based structures cannot deliver informational content (Baluška and Levin 2016). It should be noted, indeed, that environmental and social factors, either through direct physical contact or through the sharing of spaces, can shape the composition of the bacterial communities associated with individual agents. Particularly, both environmental conditions (e.g., presence of harmful substances) and social practices (e.g., dietary conducts) can have a causal role in altering the taxonomic and genetic configuration of GM, with implications for the services that it provides to the hosting agent (Archie and Tung 2015). Now, since bacterial communities within the gut can vary with the variation of external traits because of dietary habits, GM has the potential to deliver information about relevant features of the natural 
and social environment, shaping the agent's behavior accordingly (Archie and Theis 2011). On this basis, GM can be conceived as a sort of 'additional sense', allowing for informational access to the external environment through the alterations of the bacterial communities that constitute it. Thus, severe changes of GM composition, which in nature may be causally associated with dangerous traits and dysfunctional practices, may lead either to suitable behavioral responses by means of emotive reactions or to the adjustment of selected cognitive abilities such as memory and recognition. If so, this condition allows us to safely consider GM as a vehicle for informational content and leads us to include the function of the MGB axis among those endowed with cognitive significance.

Secondly, although informational content might be ascribed to GM, we do not need to take sides about the existence of non-derivative representations. Rather, it should be noted that our proposal is fully compatible with various forms of representational skepticism, from eliminativism (Churchland 1981) to instrumentalism (Dennett 1994; Egan 2013). It is possible to interpret the cognitive role of the MGB axis at the purely functional level, that is, within a framework that does not involve appealing to any informational property (Piccinini 2015). Notably, the above-mentioned evidence (see "Discovering the impact on cognitive function by the Gut Microbiota" section) suggests that the MGB axis is part of a larger causal network linking GM with the brain, thus permitting one to highlight the functional role of the MGB axis in action planning and execution. Accordingly, once the 'distinction problem' has been solved (see "The distinction problem" section), there are no further reasons to resist the proposal that cognition internally extends to GM through the MGB axis. This can be claimed even without involving any commitment to the informational nature of such a constituent.

\section{Conclusions}

In this paper, we maintain that our cognitive processes can extend through specific portions of the agent's body outside the boundaries of the nervous system and the brain. Notably, we argue that GM is a genuine vehicle of cognition and that its functions represent a peculiar case of IEC.

In order to do so, we took advantage of a variety of recent empirical data. We believe that the theoretical framework we provide here helps make sense of these empirical scientific discoveries.

However, it is important to recall that, in scientific research, new discoveries and innovations are often associated with expectations linked to a sort of explanatory hype. In this respect, new trends of research concerning the extra-intestinal functions of GM definitely show both great potential and the chance of being revolutionary, modifying our understanding not only of cognition but also of immunity, physiology, and pathology, with crucial implications for the notion of human health (Amedei and Boem 2018). However, we should not interpret microbiota's activities (and their impact) as the focus of a privileged level of explanation (over others). The risk of this type of approach is to present the study of the microbiota as a sort of 'squaring the circle', fully capable of explaining and unravelling, per se, the complexities 
of these phenomena. On the contrary, we should see this growing research field as a new, indispensable layer of complexity in our understanding of biological processes and mental phenomena.

Although today it seems that a hyperbolic enthusiasm welcomes any discovery concerning the extra-intestinal functions of GM, some scholars have started to warn the scientific community about the existence of methodological concerns regarding these findings (Hanage 2014; Hooks et al. 2018). Thus, it is important to consider these novelties without losing a critical approach. Indeed, although there is definitely significant evidence that microbiota shapes many unexpected, biological functions, including cognitive ones, a clear and detailed account of mechanisms of action is still far from being settled. That is why it appears crucial to foster this kind of research in order to provide a more comprehensive understanding (Amedei and Boem 2018).

In this respect, this theoretical condition does not exempt us from taking seriously the available results and trying to clarify their overall significance. Accordingly, our proposal should be intended as a cautious and constructive one, whose purpose is not to promote risky inferences or careless generalizations but, rather, to explore the multifaceted interactions between our cognitive apparatus and GM according to the existing evidence.

Therefore, in order to support this perspective, we have initially drawn on recent findings in the life sciences, which clearly suggest that the identity of a biological individual can be conceived as constituted by a network of functional parts, rather than defined only by species genetic fingerprints. This has allowed us to consider GM as one of the functional parts that constitute our bodily identity, although redefined. Moreover, since an increasing number of experimental results are nowadays suggesting that GM is bounded with the central nervous system through the MGB axis and that thus it exerts a plethora of functions modulating memory, emotions, and behavioral control, we have stated that GM might be legitimately considered as a functional part of our cognitive system.

Finally, we defended our proposal from possible objections, showing that there are no cogent reasons to rebut the idea that cognition is not merely a brain-based phenomenon, but that our cognitive processes internally extend to parts of the agent's body which instantiate the suitable functions, that is, GM and the MGB axis. $^{10}$

\footnotetext{
${ }^{10}$ We would like to warmly thank two anonymous reviewers for addressing important comments, both on the experimental and on the philosophical side, which led us to significantly improve the first version of this article. We would also like to thank the audiences of the Workshop on Human Nature: Philosophy and the Natural Sciences, held at the University of Milan (especially Marco Nathan, Andrea Borghini, Marco Viola, Francesca Vendola), and the one of the SILFS (Italian Association for Logic and Philosophy of Science) Postgraduate Conference, held at the University of Urbino, Carlo Bo (especially Vincenzo Fano). Gabriele Ferretti has some specific acknowledgments to do. Since the finalization of the work for the publication of the present article has been done during the transition from one research position to another, Gabriele Ferretti would like to acknowledge support from both the corresponding fellowships. This work was supported by a NOMIS Fellowship, awarded by the Eikones-Center for the Theory and History of the Image at the University of Basel, Switzerland. This work was also supported by a Humboldt Fellowship, hosted by Professor Albert Newen at the Institute for Philosophy II, RuhrUniversity Bochum, Germany.
} 
Funding Open access funding provided by Università degli Studi di Firenze within the CRUI-CARE Agreement.. No funding to declare.

Availability of data and material Not applicable.

\section{Compliance with ethical standards}

Conflict of interest We have no conflict of interest to declare. This statement is to certify that all Authors have seen and approved the manuscript being submitted. We warrant that the article is the Authors' original work. We warrant that the article has not received prior publication and is not under consideration for publication elsewhere. On behalf of all Co-Authors, the corresponding Author shall bear full responsibility for the submission. This research has not been submitted for publication nor has it been published in whole or in part elsewhere. We attest to the fact that all Authors listed on the title page have contributed significantly to the work, have read the manuscript, attest to the validity and legitimacy of the data and its interpretation, and agree to its submission to Biology \& Philosophy. All authors agree that author list is correct in its content and order and that no modification to the author list can be made without the formal approval of the Editor-in-Chief, and all authors accept that the Editor-in-Chief's decisions over acceptance or rejection or in the event of any breach of the Principles of Ethical Publishing in Biology \& Philosophy being discovered of retraction are final.

Code availability Not applicable.

Open Access This article is licensed under a Creative Commons Attribution 4.0 International License, which permits use, sharing, adaptation, distribution and reproduction in any medium or format, as long as you give appropriate credit to the original author(s) and the source, provide a link to the Creative Commons licence, and indicate if changes were made. The images or other third party material in this article are included in the article's Creative Commons licence, unless indicated otherwise in a credit line to the material. If material is not included in the article's Creative Commons licence and your intended use is not permitted by statutory regulation or exceeds the permitted use, you will need to obtain permission directly from the copyright holder. To view a copy of this licence, visit http://creativecommons.org/licen ses/by/4.0/.

\section{References}

Adams F, Aizawa K (2007) The bounds of cognition. Wiley, Amsterdam

Agustí A, García-Pardo MP, López-Almela I, Campillo I, Maes M, Romaní-Pérez M, Sanz Y (2018) Interplay between the gut-brain axis, obesity and cognitive function. Front Neurosci. https://doi. org/10.3389/fnins.2018.00155

Aizawa K (2001) The bounds of cognition. Philos Psychol 14(1):43-64. https://doi.org/10.1080/09515 080120033571

Al Omran Y, Aziz Q (2014) The brain-gut axis in health and disease. Adv ExperGMental Med Biol 817:135-153. https://doi.org/10.1007/978-1-4939-0897-4_6

Allen-Hermanson S (2013) Superdupersizing the mind: extended cognition and the persistence of cognitive bloat. Philos Stud 164(3):791-806. https://doi.org/10.1007/s11098-012-9914-7

De Almeida CV, Lulli M, Pilato V, Schiavone N, Russo E, Nannini G, Amedei A (2019) Differential responses of colorectal cancer cell lines to enterococcus faecalis' strains isolated from healthy donors and colorectal cancer patients. J Clin Med. https://doi.org/10.3390/jcm8030388

Amedei A, Boem F (2018) I've gut a feeling: microbiota impacting the conceptual and experimental perspectives of personalized medicine. Int J Mol Sci. https://doi.org/10.3390/ijms19123756

Archie EA, Theis KR (2011) Animal behaviour meets microbial ecology. Anim Behav 82(3):425-436. https://doi.org/10.1016/j.anbehav.2011.05.029

Archie EA, Tung J (2015) Social behavior and the microbiome. Curr Opin Behav Sci 6:28-34. https:// doi.org/10.1016/j.cobeha.2015.07.008 
Baars BJ, Franklin S (2003) How conscious experience and working memory interact. Trends Cognit Sci 7(4):166-172. https://doi.org/10.1016/S1364-6613(03)00056-1

Bach-y-Rita P (1967) Sensory plasticity. Applications to a vision substitution system. Acta Neurol Scand 43(4):417-426

Bagga D, Reichert JL, Koschutnig K, Aigner CS, Holzer P, Koskinen K, Moissl-Eichinger C, Schöpf V (2018) Probiotics drive gut microbiome triggering emotional brain signatures. Gut Microbes 9(6):486-496. https://doi.org/10.1080/19490976.2018.1460015

Baluška F, Levin M (2016) On having no head: cognition throughout biological systems. Front Psychol 7:902. https://doi.org/10.3389/fpsyg.2016.00902

Belkaid Y, Hand TW (2014) Role of the microbiota in immunity and inflammation. Cell 157(1):121-141. https://doi.org/10.1016/j.cell.2014.03.011

Bercik P, Collins SM (2014) The effects of inflammation, infection and antibiotics on the microbiota-gut-brain axis. Adv ExperGMental Med Biol 817:279-289. https://doi. org/10.1007/978-1-4939-0897-4_13

Bercik P, Denou E, Collins J, Jackson W, Lu J, Jury J, Collins SM (2011) The intestinal microbiota affect central levels of brain-derived neurotropic factor and behavior in mice. Gastroenterology 141(2):599-609. https://doi.org/10.1053/j.gastro.2011.04.052

Boem F, Nannini G, Amedei A (2020) Not just “immunity": how the microbiota can reshape our approach to cancer immunotherapy. Immunotherapy 12(6):407-416. https://doi.org/10.2217/imt-2019-0192

Bordenstein SR, Theis KR (2015) Host biology in light of the microbiome: ten principles of holobionts and hologenomes. PLoS Biol 13(8):1-23. https://doi.org/10.1371/journal.pbio.1002226

Bravo JA, Forsythe P, Chew MV, Escaravage E, Savignac HM, Dinan TG, Cryan JF (2011) Ingestion of Lactobacillus strain regulates emotional behavior and central GABA receptor expression in a mouse via the vagus nerve. Proc Natl Acad Sci USA 108(38):16050-16055. https://doi. org/10.1073/pnas.1102999108

Brooks AW, Kohl KD, Brucker RM, van Opstal EJ, Bordenstein SR (2017) Phylosymbiosis: relationships and functional effects of microbial communities across host evolutionary history (PLOS Biology, (2016), 14, 11, (e2000225), 10.1371/journal.pbio.2000225). PLoS Biol 15(1):1-29. https://doi. org/10.1371/journal.pbio.1002587

Brüssow H (2020) Problems with the concept of gut microbiota dysbiosis. Microb Biotechnol 13(2):423434. https://doi.org/10.1111/1751-7915.13479

Buffington SA, Prisco GVD, Auchtung TA, Ajami NJ, Petrosino JF, Costa-Mattioli M (2016) Microbial reconstitution reverses maternal diet-induced social and synaptic deficits in offspring. Cell 165(7):1762-1775. https://doi.org/10.1016/j.cell.2016.06.001

Calvani R, Picca A, Lo Monaco MR, Landi F, Bernabei R, Marzetti E (2018) Of microbes and minds: a narrative review on the second brain aging. Front Med 5:53. https://doi.org/10.3389/ fmed.2018.00053

Carabotti M, Scirocco A, Maselli MA, Severi C (2015) The gut-brain axis: interactions between enteric microbiota, central and enteric nervous systems. Ann Gastroenterol Q Publ Hellenic Soc Gastroenterol 28(2):203-209

Carlson AL, Xia K, Azcarate-Peril MA, Goldman BD, Ahn M, Styner MA, Knickmeyer RC (2018) Infant gut microbiome associated with cognitive development. Biol Psychiat 83(2):148-159. https ://doi.org/10.1016/j.biopsych.2017.06.021

Carter JA, Clark A, Kallestrup J, Palermos SO, Pritchard D (2018) Extended epistemology. OUP Oxford, Oxford

Cazettes F, Cohen JI, Yau PL, Talbot H, Convit A (2011) Obesity-mediated inflammation may damage the brain circuit that regulates food intake. Brain Res 1373:101-109. https://doi.org/10.1016/j.brain res.2010.12.008

Chevalier G, Siopi E, Guenin-Macé L et al (2020) Effect of gut microbiota on depressive-like behaviors in mice is mediated by the endocannabinoid system. Nat Commun 11:6363. https://doi. org/10.1038/s41467-020-19931-2

Churchland PM (1981) Eliminative materialism and the propositional attitudes. J Philos 78(2):67-90. https://doi.org/10.2307/2025900

Clark A (2010a) Supersizing the mind: EmbodGMent, action, and cognitive extension, 1st edn. Oxford University Press, Oxford

Clark A (2010b) Coupling, constitution and the cognitive kind: a reply to Adams and Aizawa. In: Menary (A c, Di) R (ed) The extended mind. MIT Press, Cambridge, pp 81-99 
Clark A (2010c) Supersizing the mind: embodiment, action, and cognitive extension (1 edition). Oxford University Press

Clarke E (2010) The Problem of Biological Individuality. Biol Theory 5:312-325. https://doi. org/10.1162/BIOT_a_00068

Clark A, Chalmers D (1998) The extended mind. Analysis 58(1):7-19. https://doi.org/10.2307/3328150

Cummings JL, Barritt CF, Horan M (1986) Delusions induced by procaine penicillin: case report and review of the syndrome. Int J Psychiat Med 16(2):163-168

Damasio AR (2005) Descartes' error: emotion. Penguin Group USA, Reason, And the Human Brain (Reprint)

Dennett DC (1994) The myth of original intentionality. In: Dietrich E (A c. Di), Thinking computers and virtual persons, pp 91-107. Academic Press. https://doi.org/https://doi.org/10.1016/B978$0-12-215495-9.50009-0$

Dinan TG, Cryan JF (2017) Gut instincts: microbiota as a key regulator of brain development, ageing and neurodegeneration. J Physiol 595(2):489-503. https://doi.org/10.1113/JP273106

Dretske F (1995) Naturalizing the mind. MIT Press

Eberl G (2010) A new vision of immunity: homeostasis of the superorganism. Mucosal Immunol 3(5):450-460. https://doi.org/10.1038/mi.2010.20

Egan F (2013) How to think about mental content. Philos Stud 1:1-21

Fernandez-Real J-M, Serino M, Blasco G, Puig J, Daunis-i-Estadella J, Ricart W, Portero-Otin M (2015) Gut microbiota interacts with brain microstructure and function. J Clin Endocrinol Metabol 100(12):4505-4513. https://doi.org/10.1210/jc.2015-3076

Fetissov SO (2017) Role of the gut microbiota in host appetite control: bacterial growth to animal feeding behaviour. Nat Rev Endocrinol 13(1):11-25. https://doi.org/10.1038/nrendo.2016.150

Finegold SM (2011) Desulfovibrio species are potentially important in regressive autism. Med Hypotheses 77(2):270-274. https://doi.org/10.1016/j.mehy.2011.04.032

Fodor JA (1990) A theory of content and other essays. MIT Press

Forsythe P, Kunze WA (2013) Voices from within: gut microbes and the CNS. Cell Mol Life Sci 70(1):55-69. https://doi.org/10.1007/s00018-012-1028-z

Forsythe P, Bienenstock J, Kunze WA (2014) Vagal pathways for microbiome-braingut axis communication. Adv ExperGMental Med Biol 817:115-133. https://doi. org/10.1007/978-1-4939-0897-4_5

Foster JA, McVey Neufeld K-A (2013) Gut-brain axis: how the microbiome influences anxiety and depression. Trends Neurosci 36(5):305-312. https://doi.org/10.1016/j.tins.2013.01.005

Foster JA, Rinaman L, Cryan JF (2017a) Stress \& the gut-brain axis: regulation by the microbiome. Neurobiol Stress 7:124-136. https://doi.org/10.1016/j.ynstr.2017.03.001

Foster KR, Schluter J, Coyte KZ, Rakoff-Nahoum S (2017b) The evolution of the host microbiome as an ecosystem on a leash. Nature. https://doi.org/10.1038/nature23292

Frost G, Sleeth ML, Sahuri-Arisoylu M, Lizarbe B, Cerdan S, Brody L, Anastasovska J, Ghourab S, Hankir M, Zhang S, Carling D, Swann JR, Gibson G, Viardot A, Morrison D, Thomas EL, Bell JD (2014) The short-chain fatty acid acetate reduces appetite via a central homeostatic mechanism. Nat Commun 5(1):1-11. https://doi.org/10.1038/ncomms4611

Gallagher S (2018) The extended mind: state of the question. Southern J Philos 56:421-447. https:// doi.org/10.1111/sjp.12308

Gareau MG (2014) Microbiota-gut-brain axis and cognitive function. Adv ExperGMental Med Biol 817:357-371. https://doi.org/10.1007/978-1-4939-0897-4_16

Gareau MG, Wine E, Rodrigues DM, Cho JH, Whary MT, Philpott DJ, Sherman PM (2011) Bacterial infection causes stress-induced memory dysfunction in mice. Gut 60(3):307-317. https://doi. org/10.1136/gut.2009.202515

Gibbs-Gallagher N, Palsson OS, Levy RL, Meyer K, Drossman DA, Whitehead WE (2001) Selective recall of gastrointestinal-sensation words: evidence for a cognitive-behavioral contribution to irritable bowel syndrome. Am J Gastroenterol 96(4):1133-1138. https://doi.org/10.111 1/j.1572-0241.2001.03759.x

Gilbert JA, Blaser MJ, Caporaso JG, Jansson JK, Lynch SV, Knight R (2018) Current understanding of the human microbiome. Nat Med 24(4):392-400. https://doi.org/10.1038/nm.4517

Gilbert SF (2019) Developmental symbiosis facilitates the multiple origins of herbivory. Evol Dev. https://doi.org/10.1111/ede.12291

Gilbert SF, Sapp J, Tauber AI (2012) A symbiotic view of life: we have never been individuals. Q Rev Biol 87(4):325-341. https://doi.org/10.1086/668166 
Godfrey-Smith P (2013) Darwinian individuals. In: Bouchard F, Huneman P (eds) From groups to individuals: evolution and emerging individuality. MIT Press, Cambridge, pp 17-36

Góra B, Gofron Z, Grosiak M, Aptekorz M, Kazek B, Kocelak P, Radosz-Komoniewska H, Chudek J, Martirosian G (2018) Toxin profile of fecal Clostridium perfringens strains isolated from children with autism spectrum disorders. Anaerobe 51:73-77. https://doi.org/10.1016/j.anaer obe.2018.03.005

Grenham S, Clarke G, Cryan JF, Dinan TG (2011) Brain-gut-microbe communication in health and disease. Front Physiol. https://doi.org/10.3389/fphys.2011.00094

Hanage WP (2014) Microbiology: microbiome science needs a healthy dose of scepticism. Nat News 512(7514):247. https://doi.org/10.1038/512247a

Hoban AE, Stilling RM, Moloney G, Shanahan F, Dinan TG, Clarke G, Cryan JF (2018) The microbiome regulates amygdala-dependent fear recall. Mol Psychiat 23(5):1134-1144. https://doi.org/10.1038/ mp. 2017.100

Hooks KB, Konsman JP, O’Malley MA (2018) Microbiota-gut-brain research: a critical analysis. Behav Brain Sci. https://doi.org/10.1017/S0140525X18002133

Hooks KB, O’Malley MA (2017) Dysbiosis and its discontents. MBio 8(5):1-11. https://doi.org/10.1128/ mBio.01492-17

Houlden A, Goldrick M, Brough D, Vizi ES, Lénárt N, Martinecz B, Denes A (2016) Brain injury induces specific changes in the caecal microbiota of mice via altered autonomic activity and mucoprotein production. Brain Behav Immun 57:10-20. https://doi.org/10.1016/j.bbi.2016.04.003

Huitzil S, Sandoval-Motta S, Frank A, Aldana M (2018) Modeling the role of the microbiome in evolution. Front Physiol. https://doi.org/10.3389/fphys.2018.01836

Hurley S (2001) Perception and action: alternative views. Synthese 129(1):3-40. https://doi. org/10.1023/A:1012643006930

Jiang C, Li G, Huang P, Liu Z, Zhao B (2017) The gut microbiota and alzheimer's disease. J Alzheimer's Dis JAD 58(1):1-15. https://doi.org/10.3233/JAD-161141

Johnson KVA, Foster KR (2018a) Why does the microbiome affect behaviour? Nat Rev Microbiol. https ://doi.org/10.1038/s41579-018-0014-3

Johnson KV-A, Foster KR (2018b) Why does the microbiome affect behaviour? Nat Rev Microbiol 16(10):647-655. https://doi.org/10.1038/s41579-018-0014-3

Karl JP, Hatch AM, Arcidiacono SM, Pearce SC, Pantoja-Feliciano IG, Doherty LA, Soares JW (2018) Effects of psychological, environmental and physical stressors on the gut microbiota. Front Microbiol. https://doi.org/10.3389/fmicb.2018.02013

Kass JS, Shandera WX (2010) Nervous system effects of antituberculosis therapy. CNS Drugs 24(8):655667. https://doi.org/10.2165/11534340-000000000-00000

Kelly JR, Minuto C, Cryan JF, Clarke G, Dinan TG (2017) Cross talk: the microbiota and neurodevelopmental disorders. Front Neurosci 11:490. https://doi.org/10.3389/fnins.2017.00490

Kiraly D, Walker D, Calipari E et al (2016) Alterations of the Host Microbiome Affect Behavioral Responses to Cocaine. Sci Rep 6:35455. https://doi.org/10.1038/srep35455

Klassen JL (2019) Ecology helps bound causal explanations in microbiology. Biol Philos 35(1):3. https:// doi.org/10.1007/s10539-019-9728-5

Kowalski K, Mulak A (2019) Brain-gut-microbiota axis in alzheimer's disease. J Neurogastroenterol Motility 25(1):48-60. https://doi.org/10.5056/jnm18087

Lean CH (2019) Can communities cause? Biol Philos 34(6):59. https://doi.org/10.1007/s1053 9-019-9715-X

Ley RE, Turnbaugh PJ, Klein S, Gordon JI (2006) Human gut microbes associated with obesity. Nature 444(7122):1022-1023. https://doi.org/10.1038/4441022a

Li XJ, You XY, Wang CY, Li XL, Sheng YY, Zhuang PW, Zhang YJ (2020) Bidirectional brain-gutmicrobiota axis in increased intestinal permeability induced by central nervous system injury. CNS Neurosci Therapeut 26(8):783-790. https://doi.org/10.1111/cns.13401

Lozupone CA, Stombaugh JI, Gordon JI, Jansson JK, Knight R (2012) Diversity, stability and resilience of the human gut microbiota. Nature 489(7415):220-230. https://doi.org/10.1038/nature11550

Ludwig D (2015) Extended cognition and the explosion of knowledge. Philos Psychol 28(3):355-368. https://doi.org/10.1080/09515089.2013.867319

Lynch KE, Parke EC, O'Malley MA (2019) How causal are microbiomes? A comparison with the Helicobacter pylori explanation of ulcers. Biol Philos. https://doi.org/10.1007/s10539-019-9702-2

Lyte M, Cryan(A c. Di) JF (2014) Microbial endocrinology: the microbiota-gut-brain axis in health and disease. Springer. https://doi.org/10.1007/978-1-4939-0897-4 
Madl T, Baars BJ, Franklin S (2011) The timing of the cognitive cycle. PLoS ONE 6(4):e14803. https:// doi.org/10.1371/journal.pone.0014803

Marsh L (2010) Introduction to the special issue "Extended Mind." Cognit Syst Res 11(4):311-312. https ://doi.org/10.1016/j.cogsys.2010.06.003

Mayer EA, Savidge T, Shulman RJ (2014) Brain gut microbiome interactions and functional bowel disorders. Gastroenterology 146(6):1500-1512. https://doi.org/10.1053/j.gastro.2014.02.037

McCue JD, Zandt JR (1991) Acute psychoses associated with the use of ciprofloxacin and trGMethoprGM-sulfamethoxazole. Am J Med 90(4):528-529

Menary R (2010) The extended mind. Recuperato da https://researchers.mq.edu.au/en/publications/theextended-mind

Millikan RG (2009) Biosemantics. In: BP McLaughlin, A Beckerman (A c. Di), Journal of Philosophy, pp 281-297. Oxford University Press

Murphy TH, Corbett D (2009) Plasticity during stroke recovery: from synapse to behaviour. Nat Rev Neurosci 10(12):861-872. https://doi.org/10.1038/nrn2735

Nanay B (2014) Teleosemantics without etiology. Philos Sci 81(5):798-810. https://doi. org/10.1086/677684

Nature editorial (2019) Links between gut microbes and depression strengthened. Nature 566(7742):7. https://doi.org/10.1038/d41586-019-00483-5

Neander K (2017) A mark of the mental: In: Defense of Informational Teleosemantics (1 edition). The MIT Press

Neufeld KM, Kang N, Bienenstock J, Foster JA (2011) Reduced anxiety-like behavior and central neurochemical change in germ-free mice. Neurogastroenterol Motil 23(3):255-e119. https://doi.org/10.1 111/j.1365-2982.2010.01620.x

Niccolai E, Boem F, Russo E, Amedei A (2019) The gut-brain axis in the neuropsychological disease model of obesity : a classical movie revised by the emerging director " microbiome." Nutrients. https://doi.org/10.3390/nu11010156

Nicholson DJ (2014) The Return of the Organism as a Fundamental Explanatory Concept in Biology. Philosophy Compass 9:347-359. https://doi.org/10.1111/phc3.12128

Noë A (2004) Action in perception. MIT Press

Novotný M, Klimova B, Valis M (2019) Microbiome and cognitive impairment: can any diets influence learning processes in a positive way? Front Aging Neurosci. https://doi.org/10.3389/fnagi .2019 .00170

O’Donnell MP, Fox BW, Chao PH, Schroeder FC, Sengupta P (2020) A neurotransmitter produced by gut bacteria modulates host sensory behaviour. Nature. 583(7816):415-420. https://doi.org/10.1038/ s41586-020-2395-5

Oatley K, Johnson-Laird PN (2014) Cognitive approaches to emotions. Trends Cognit Sci 18(3):134140. https://doi.org/10.1016/j.tics.2013.12.004

Okasha S (2006) Evolution and the levels of selection. Clarendon Press, Oxford University Press, Oxford

Okon-Singer H, Hendler T, Pessoa L, Shackman AJ (2015) The neurobiology of emotion-cognition interactions: fundamental questions and strategies for future research. Front Hum Neurosci. https://doi. org/10.3389/fnhum.2015.00058

Ongür D, Price JL (2000) The organization of networks within the orbital and medial prefrontal cortex of rats, monkeys and humans. Cerebral Cortex (NY 1991) 10(3):206-219

Palermos OS (2014) Loops, constitution, and cognitive extension. Cognit Syst Res 27:25-41. https://doi. org/10.1016/j.cogsys.2013.04.002

Pennisi E (2020) Meet the psychobiome. Science 368(6491):570-573. https://doi.org/10.1126/scien ce.368.6491.570

Perez-Burgos A, Mao Y-K, Bienenstock J, Kunze WA (2014) The gut-brain axis rewired: adding a functional vagal nicotinic «sensory synapse». FASEB J 28(7):3064-3074. https://doi.org/10.1096/fj.13245282

Pessoa L (2008) On the relationship between emotion and cognition. Nat Rev Neurosci 9(2):148-158. https://doi.org/10.1038/nrn2317

Piccinini G (2004) Functionalism, computationalism, \& mental states. Stud Hist Philos Sci 35(4):811833. https://doi.org/10.1016/j.shpsa.2004.02.003

Piccinini G (2015) Physical computation: a mechanistic account. OUP Oxford

Piredda G (2017) The mark of the cognitive and the coupling-constitution fallacy: a defense of the extended mind hypothesis. Front Psychol 8:2061. https://doi.org/10.3389/fpsyg.2017.02061

Pradeu T (2012) The limits of the self: immunology and biological identity. Oxford University Press 
Pradeu T (2016) The many faces of biological individuality. Biol Philos 31:761-773. https://doi. org/10.1007/s10539-016-9553-z

Prinz JJ (2006) Gut reactions: a perceptual theory of emotion. Oxford University Press

Putnam H (1960) Minds and machines. In: S Hook (A c. Di), Journal of Symbolic Logic, pp 57-80. New York University Press

Putnam H (1967) The nature of mental states. In: WH Capitan, DD Merrill (A c. Di) Art, mind, and religion, pp 1-223. Pittsburgh University Press

Qin J, Li R, Raes J, Arumugam M, Burgdorf KS, Manichanh C, Wang J (2010) A human gut microbial gene catalogue established by metagenomic sequencing. Nature 464(7285):59-65. https://doi. org/10.1038/nature08821

Rees T, Bosch T, Douglas AE (2018) How the microbiome challenges our concept of self. PLoS Biol 16(2):e2005358. https://doi.org/10.1371/journal.pbio.2005358

Rhee SH, Pothoulakis C, Mayer EA (2009) Principles and clinical implications of the brain-gut-enteric microbiota axis. Nat Rev Gastroenterol Hepatol 6(5):306-314. https://doi.org/10.1038/nrgas tro.2009.35

Ringel Y, Maharshak N (2013) Intestinal microbiota and Immune function in the pathogenesis of irritable bowel syndrome. Am J Physiol Gastrointest Liver Physiol 305(8):G529-G541. https://doi. org/10.1152/ajpgi.00207.2012

Roger AJ, Muñoz-Gómez SA, Kamikawa R (2017) The origin and diversification of mitochondria. Curr Biology CB 27(21):R1177-R1192. https://doi.org/10.1016/j.cub.2017.09.015

Ronai I, Greslehner GP, Boem F, Carlisle J, Stencel A, Suárez J et al (2020) "Microbiota, symbiosis and individuality summer school" meeting report. Microbiome 8(1):117. https://doi.org/10.1186/s4016 8-020-00898-7

Rook G, Bäckhed F, Levin BR, McFall-Ngai MJ, McLean AR (2017) Evolution, human-microbe interactions, and life history plasticity. Lancet Lond Engl 390(10093):521-530. https://doi.org/10.1016/ S0140-6736(17)30566-4

Rupert RD (2004) Challenges to the hypothesis of extended cognition. J Philos 101(8):389-428

Sanguinetti E, Guzzardi MA, Tripodi M, Panetta D, Selma-Royo M, Zega A, Iozzo P (2019) Microbiota signatures relating to reduced memory and exploratory behaviour in the offspring of overweight mothers in a murine model. Sci Rep. https://doi.org/10.1038/s41598-019-48090-8

Sarkar A, Harty S, Lehto SM, Moeller AH, Dinan TG, Dunbar RIM, Burnet PWJ (2018) The microbiome in psychology and cognitive neuroscience. Trends Cognit Sci 22(7):611-636. https://doi. org/10.1016/j.tics.2018.04.006

Sarkar A, Lehto SM, Harty S, Dinan TG, Cryan JF, Burnet PWJ (2016) Psychobiotics and the manipulation of bacteria-gut-brain signals. Trends Neurosci 39(11):763-781. https://doi.org/10.1016/j. tins.2016.09.002

Scheperjans F, Aho V, Pereira PAB, Koskinen K, Paulin L, Pekkonen E, Auvinen P (2015) Gut microbiota are related to Parkinson's disease and clinical phenotype. Mov Disord 30(3):350-358. https:// doi.org/10.1002/mds.26069

Sharon G, Sampson TR, Geschwind DH, Mazmanian SK (2016) The central nervous system and the gut microbiome. Cell 167(4):915-932. https://doi.org/10.1016/j.cell.2016.10.027

Sherwin E, Bordenstein SR, Quinn JL, Dinan TG, Cryan JF (2019) Microbiota and the social brain. Science 366(6465):eaar2016. https://doi.org/10.1126/science.aar2016

Slykerman RF, Thompson J, Waldie KE, Murphy R, Wall C, Mitchell EA (2017) Antibiotics in the first year of life and subsequent neurocognitive outcomes. Acta Paediatr 106(1):87-94. https://doi. org/10.1111/apa.13613

Son JS, Zheng LJ, Rowehl LM, Tian X, Zhang Y, Zhu W, Litcher-Kelly L, Gadow KD, Gathungu G, Robertson CE, Ir D, Frank DN, Li E (2015) Comparison of fecal microbiota in children with autism spectrum disorders and neurotypical siblings in the simons simplex collection. PLoS ONE 10(10):e0137725. https://doi.org/10.1371/journal.pone.0137725

Storbeck J, Clore GL (2007) On the interdependence of cognition and emotion. Cogn Emot 21(6):12121237. https://doi.org/10.1080/02699930701438020

Strandwitz P (2018) Neurotransmitter modulation by the gut microbiota. Brain Res 1693:128-133. https ://doi.org/10.1016/j.brainres.2018.03.015

Strandwitz P, Kim KH, Terekhova D, Liu JK, Sharma A, Levering J, Lewis K (2019) GABA-modulating bacteria of the human gut microbiota. Nat Microbiol. https://doi.org/10.1038/s41564-018-0307-3

Suárez J (2018a) Adams, Fred, and Aizawa, K. (2001). The bounds of cognition. Philos Psychol 14(1):43-64. https://doi.org/10.1080/09515080120033571 
Suárez J (2018b) The importance of symbiosis in philosophy of biology: an analysis of the current debate on biological individuality and its historical roots. Symbiosis 76(2):77-96. https://doi.org/10.1007/ s13199-018-0556-1

Suárez J, Stencel A (2020) A part-dependent account of biological individuality: why holobionts are individuals and ecosystems simultaneously. Biol Rev. https://doi.org/10.1111/brv.12610

The Human Microbiome Project Consortium, Huttenhower C, Gevers D, Knight R, Abubucker S, Badger JH, White O (2012) Structure, function and diversity of the healthy human microbiome. Nature 486(7402):207-214. https://doi.org/10.1038/nature11234

Tillisch K, Labus J, Kilpatrick L, Jiang Z, Stains J, Ebrat B, MayeR EA (2013) Consumption of fermented milk product with probiotic modulates brain activity. Gastroenterology. https://doi.org/10.1053/j. gastro.2013.02.043

Tillisch K, Mayer EA, Gupta A, Gill Z, Brazeilles R, Le Nevé B, van Hylckama Vlieg JET, Guyonnet D, Derrien M, Labus JS (2017) Brain structure and response to emotional stimuli as related to gut microbial profiles in healthy women. Psychosom Med 79(8):905-913. https://doi.org/10.1097/ PSY.0000000000000493

Valles-Colomer M, Falony G, Darzi Y, Tigchelaar EF, Wang J, Tito RY, Raes J (2019) The neuroactive potential of the human gut microbiota in quality of life and depression. Nat Microbiol. https://doi. org/10.1038/s41564-018-0337-x

Walf AA, Frye CA (2007) The use of the elevated plus maze as an assay of anxiety-related behavior in rodents. Nat Protoc 2(2):322-328. https://doi.org/10.1038/nprot.2007.44

Wang T, Hu X, Liang S, Li W, Wu X, Wang L, Jin F (2015) Lactobacillus fermentum NS9 restores the antibiotic induced physiological and psychological abnormalities in rats. Benef Microb 6(5):707717. https://doi.org/10.3920/BM2014.0177

Wilson RA (2014) Ten questions concerning extended cognition. Philos Psychol 27(1):19-33. https://doi. org/10.1080/09515089.2013.828568

Yano JM, Yu K, Donaldson GP, Shastri GG, Ann P, Ma L, Hsiao EY (2015) Indigenous bacteria from the gut microbiota regulate host serotonin biosynthesis. Cell 161(2):264-276. https://doi.org/10.1016/j. cell.2015.02.047

Yoo BB, Mazmanian SK (2017) The enteric network: interactions between the immune and nervous systems of the gut. Immunity 46(6):910-926. https://doi.org/10.1016/j.immuni.2017.05.011

Zhao L, Xiong Q, Stary CM, Mahgoub OK, Ye Y, Gu L, Zhu S (2018) Bidirectional gut-brain-microbiota axis as a potential link between inflammatory bowel disease and ischemic stroke. J Neuroinflam 15(1):1-11. https://doi.org/10.1186/s12974-018-1382-3

Publisher's Note Springer Nature remains neutral with regard to jurisdictional claims in published maps and institutional affiliations.

\section{Authors and Affiliations}

\section{Federico Boem ${ }^{1}$ (D) $\cdot$ Gabriele Ferretti ${ }^{2,3} \cdot$ Silvano Zipoli Caiani ${ }^{1}$}

Gabriele Ferretti

fairg@live.it

Silvano Zipoli Caiani

silvano.zipolicaiani@unifi.it

1 Dipartimento di Lettere e Filosofia, Università Degli Studi Di Firenze, via della Pergola, 60, 50121 Firenze, Italy

2 Institute for Philosophy II, Ruhr-University Bochum, GA 3/151, Universitätsstr. 150, 44780 Bochum, Germany

3 Eikones - Center for the Theory and History of the Image, University of Basel, Rheinsprung 11, 4051 Basel, Switzerland 